Brit. Heart F., 1966, 28, 184.

\title{
Morphology of the Intestinal Arterioles in Chronic Human Hypertension
}

\author{
DAVID SHORT \\ From Woodend General Hospital and The Royal Infirmary, Aberdeen
}

The nature of the increased vascular resistance in chronic hypertension has been the subject of much investigation and speculation. The evidence strongly suggests that this resistance is mainly at arteriolar level; hence the arterioles are often referred to as the resistance vessels. When hypertension was first recognized, it was thought that structural changes in the arterioles and capillaries might account for the increased resistance (Gull and Sutton, 1872), but these changes could not subsequently be confirmed. More recently, Folkow (1956) has suggested that medial hypertrophy might have the effect of narrowing the lumen; but so far as the author is aware, the existence of medial hypertrophy in the arterioles has never been established by actual measurements of the cross-sectional area of the wall, as Barrett (1963) did so elegantly in the case of the larger arteries. It has been clearly shown that the arteriolar wall/lumen ratio is increased in hypertension (Kernohan, Anderson, and Keith, 1929; Morlock, 1939), but this does not necessarily indicate an increase in the substance of the wall; it could be due to a decrease in diameter.

Satisfactory measurements cannot be made on arterioles in ordinary histological preparations because the vessels are collapsed and contracted. Since they are collapsed, they appear flattened in cross-section instead of being circular, and this makes it impossible to obtain a valid measure of diameter. Because they are contracted-and contracted to varying degrees (MacWilliam and Mackie, 1908) as shown by differing degrees of undulation of the internal elastic lamina-the wall/lumen ratio is of limited significance. Both these difficulties can be overcome by distending the arterioles to such a degree that the internal elastic lamina

Received June 2, 1965. becomes completely smooth. This makes all the arterioles cylindrical, so that the diameter can be measured accurately. It also abolishes the varying degree of contraction and makes it possible to measure all the arterioles in the same state. This method has the further great advantage that all arterioles in a section can be measured, not only those cut at right angles; for, however obliquely a distended vessel may be cut, the shortest diameter is the true diameter. Distending the arterioles should not be regarded as an unnatural procedure. On the contrary, by reproducing the systolic pressure existing during life, it is likely that the calibre of these vessels is restored to a more natural state than exists in uninjected post-mortem material (Van Citters, Wagner, and Rushmer, 1962).

The small intestine was chosen for this study because the evidence suggests that this is a representative portion of the peripheral vascular bed in hypertension. It is also usually readily available at necropsy. In our first report on this work (Short and Thomson, 1959) we compared the crosssectional area of the wall and the wall/lumen ratio of arteries in the mesentery (the vasa recta) in hypertensive and control cases, and also described the arteriographic appearances of the vessels in the intestinal wall. But at that time we could not think of any satisfactory way of measuring the apparent difference in the morphology of the arterioles in the hypertensive and control cases. In this paper the measurements made on the arterioles have been submitted to a more detailed analysis.

\section{SubJeCts AND Methods}

The aim of the study was to compare cases of chronic hypertension with matched controls. To be accepted as a case of chronic hypertension, there had to be definite left ventricular hypertrophy as well as evidence of high 
TABLE I

DETAILS OF CASES STUDIED

\begin{tabular}{|c|c|c|c|c|c|c|c|c|}
\hline \multicolumn{3}{|c|}{$\begin{array}{l}\text { Case, age (yr.), } \\
\text { and sex }\end{array}$} & Diagnosis & $\begin{array}{l}\text { Maximum } \\
\text { recorded } \\
\text { blood pressure } \\
(\mathrm{mm} . \mathrm{Hg})\end{array}$ & \multirow[t]{3}{*}{$\begin{array}{c}\text { Duration } \\
\text { of hypertension }\end{array}$} & $\begin{array}{l}\text { Heart } \\
\text { weight } \\
\text { (g.) }\end{array}$ & $\begin{array}{c}\text { Left } \\
\text { ventricular } \\
\text { hypertrophy }\end{array}$ & Comments \\
\hline $\begin{array}{l}\text { Control } \\
\text { N.D. }\end{array}$ & 44 & $\mathbf{F}$ & Pulmonary fibrosis & $120 / 80$ & & 425 & 0 & Right ventricular \\
\hline $\begin{array}{l}\text { G.H. } \\
\text { E.W. } \\
\text { J.N. } \\
\text { F.H. } \\
\text { H.S. }\end{array}$ & $\begin{array}{l}47 \\
55 \\
61 \\
78 \\
78\end{array}$ & $\begin{array}{l}\mathbf{M} \\
\mathbf{F} \\
\mathbf{M} \\
\mathrm{F} \\
\mathbf{M}\end{array}$ & $\begin{array}{l}\text { Carcinoma of kidney } \\
\text { Carcinoma of tonsil } \\
\text { Cardiac infarction } \\
\text { Carcinoma of breast } \\
\text { Carcinoma of cæcum }\end{array}$ & $\begin{array}{l}140 / 90 \\
96 / 65 \\
140 / 100 \\
120 / 50 \\
180 / 110\end{array}$ & & $\begin{array}{c}370 \\
285 \\
510 \\
455 \\
?\end{array}$ & $\begin{array}{l}0 \\
0 \\
+ \\
0 \\
0\end{array}$ & Epicardial fat ++ \\
\hline $\begin{array}{l}\text { Hyperte } \\
\text { W.M. }\end{array}$ & $\begin{array}{l}\text { nsive } \\
42\end{array}$ & $\mathbf{M}$ & $\begin{array}{l}\text { Essential hypertension } \\
\text { (malignant phase) }\end{array}$ & $260 / 150$ & $>7$ mith. & 795 & + & \\
\hline $\begin{array}{l}\text { H.L. } \\
\text { J.S. }\end{array}$ & $\begin{array}{l}51 \\
68\end{array}$ & $\begin{array}{l}\mathbf{M} \\
\mathbf{M}\end{array}$ & $\begin{array}{l}\text { Essential hypertension } \\
\text { Essential hypertension; } \\
\text { cardiac infarction }\end{array}$ & $160 / 120$ & $?$ & $\begin{array}{l}680 \\
765\end{array}$ & $\begin{array}{l}+ \\
+\end{array}$ & \\
\hline $\begin{array}{l}\text { R.F. } \\
\text { E.C. }\end{array}$ & $\begin{array}{l}71 \\
72\end{array}$ & $\underset{\mathbf{M}}{\mathbf{F}}$ & $\begin{array}{l}\text { Essential hypertension } \\
\text { Essential hypertension }\end{array}$ & $\begin{array}{l}230 / 130 \\
240 / 130\end{array}$ & $\begin{array}{l}>6 \mathrm{yr} . \\
14 \mathrm{yr} .\end{array}$ & $\begin{array}{l}425 \\
540\end{array}$ & $\begin{array}{l}+ \\
+\end{array}$ & $\begin{array}{l}\text { Stenosis of } \\
\text { superior } \\
\text { mesenteric }\end{array}$ \\
\hline A.T. & 82 & $\mathbf{F}$ & $\begin{array}{l}\text { Essential hypertension; } \\
\text { myelomatosis }\end{array}$ & $300 / 140$ & $>5$ mth. & 510 & + & artery \\
\hline
\end{tabular}

blood pressure (diastolic pressure $120 \mathrm{~mm}$. Hg or over). The left ventricle was regarded as hypertrophied if its wall was over $1.5 \mathrm{~cm}$. thick, and the heart weighed over $510 \mathrm{~g}$. in a man or over $370 \mathrm{~g}$. in a woman. Cases without evidence of prolonged elevation of blood pressure were used as controls.

The initial selection of cases for study was made by the pathologist responsible for routine necropsies. Whereever possible a case of chronic hypertension and a control were studied on the same day. It was sometimes necessary to reclassify a case when all the clinical and pathological evidence became available, but cases were only discarded if the injection was technically unsatisfactory. After 12 cases had been satisfactorily injected, it was found that there were 6 examples of chronic hypertension and 6 controls reasonably well matched in regard to age and sex (Table I).

Two cases, believed at the time of injection to be examples of chronic hypertension, had later to be transferred to the control group. One (J.N.) was thought at necropsy to have been hypertensive because of the presence of left ventricular hypertrophy; but it was subsequently found that the highest blood pressure recorded during life was only $140 / 100 \mathrm{~mm}$. $\mathrm{Hg}$ : he had had repeated myocardial infarcts, and this was regarded as the possible cause of the ventricular hypertrophy. The other (H.S.) was known to have had a raised blood pressure $(180 / 110 \mathrm{~mm}$. $\mathrm{Hg})$, but he had no left ventricular hypertrophy. One (H.L.) was accepted as an example of chronic hypertension in spite of the fact that there was no record of blood pressure: this patient had left ventricular hypertrophy without any other disease of the heart, classical hypertensive changes in the kidneys, and a fatal intracerebral hæmorrhage.

The aim was to distend all the branches of the superior mesenteric artery down to the smallest arterioles to such a degree that their internal elastic laminæ became quite smooth (Fig. 1). In a preliminary study it was found that such distension could usually be achieved by perfusing the superior mesenteric artery with a warm ammoniacal solution, and then injecting a suspension of bismuth oxychloride in gelatin, heated to $80^{\circ} \mathrm{C}$. , at a pressure within the range 150-250 mm. Hg. (Full details of the technique are given in the paper by Short and Thomson, 1959.)

All cases were dealt with in the same way, except that the hypertensive ones were injected at somewhat higher pressures than the controls (200-250 mm. Hg, compared with $150 \mathrm{~mm} . \mathrm{Hg}$ ) in order to make sure of overcoming post-mortem contraction. The two cases which were believed at the time of injection to be hypertensive, but were later allocated to the control group, were injected at the higher pressures.

Immediately after the injection, the small intestine was gently distended with formalin and immersed in the fixative. After fixation, portions of intestinal wall, taken from approximately the middle of the small intestine, were removed for radiographic examination. Duplicate histological sections were made from the counter-mesenteric border, one set being stained with hæmatoxylin and eosin, and the other with elastic and van Gieson. The sections were examined to ensure that the injection medium had penetrated to arterioles of $20 \mu$ internal diameter and that all arterioles larger than this had been distended to such a degree that their internal elastic laminæ were quite smooth (Fig. 1). Cases in which this was not achieved were rejected.

Sections of intestinal wall, $2 \mathrm{~cm}$. in length, were marked off on the slides, and the diameter and wall thick-

* This high temperature was necessary to allow for the cooling which takes place during the slow passage of the viscous suspension down the injection system. 

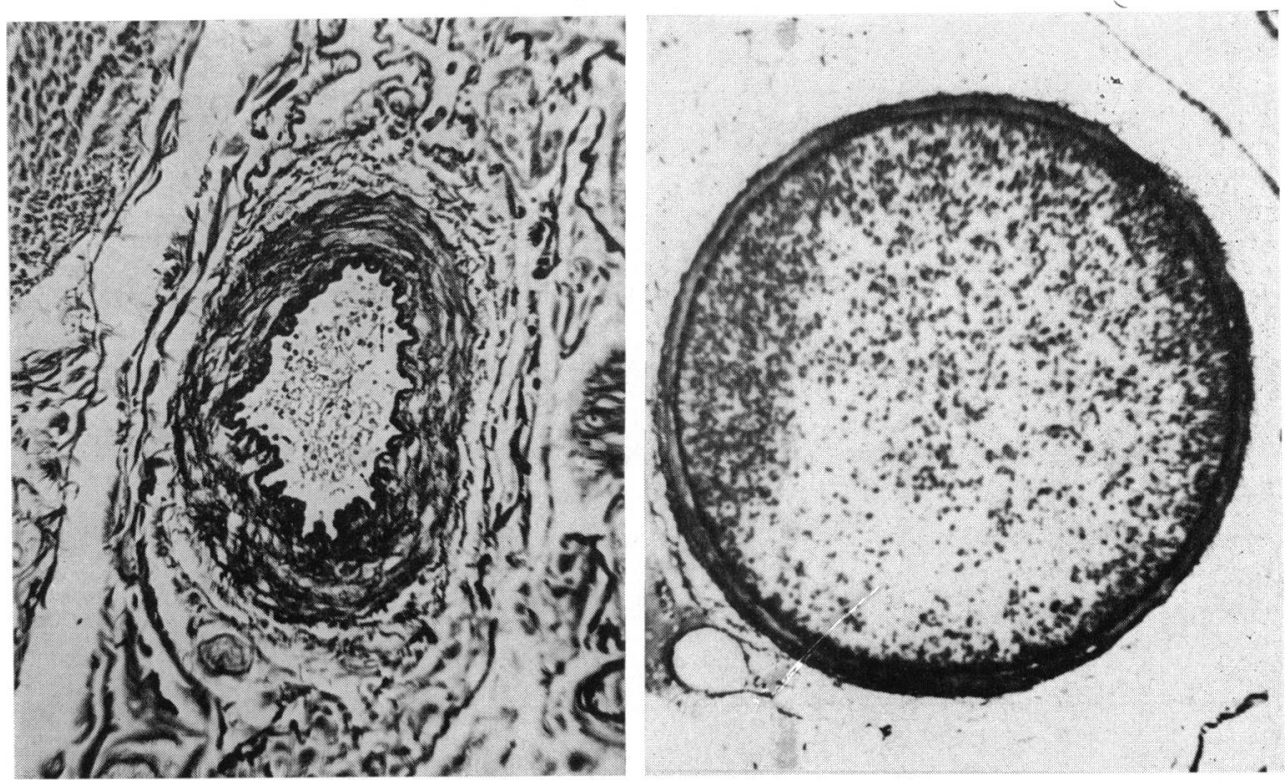

Fig. 1.-Arteries in the wall of the small intestine: uninjected and injected. Both these arteries are taken from the wall of the small intestine in a case of chronic hypertension (Case H.L.). Left: Artery from an uninjected portion of the intestine, showing marked undulation of the internal elastic lamina. (Size $300 \times$ $200 \mu$.) Right: Artery from the injected portion of the intestine, showing a completely smooth elastic coat indicating a high degree of distension. (Diameter $420 \mu$.) (Elastic and van Gieson.)

Reproduced by permission of the Editor of $\mathcal{F}$. Path. Bact.

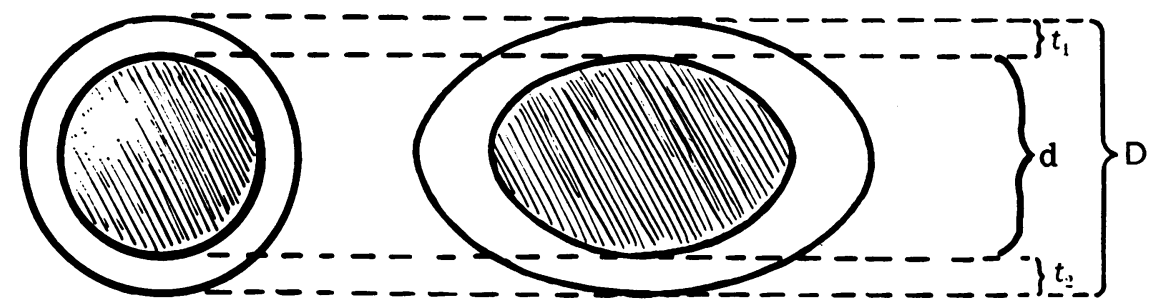

FIG. 2.-Indicates how the arteries were measured. $D, t_{1}$, and $t_{2}$ were measured; and from these measurements, the internal diameter $(d)$, the wall/lumen ratio $\left(\frac{t_{1}+t_{2}}{d}\right)$, and the cross-sectional area of the wall $\left(\pi\left(\frac{D}{2}\right)^{2}-\pi\left(\frac{d}{2}\right)^{2}\right)$ were calculated.

ness of all the injected arterioles between the marks were measured (Fig. 2). In the case of arterioles cut obliquely, the shortest diameter and the thickness of the wall on this line were taken as the true measurements. From these basic measurements, the wall/lumen ratio $\frac{\left(t_{1}+t_{2}\right)}{d}$ and the cross-sectional area of the wall $\left(\pi\left(\frac{D}{2}\right)^{2}-\pi\left(\frac{d}{2}\right)^{2}\right)$ were calculated.

There were slightly fewer arterioles in the hyperten- sive series than in the control series, 204 compared with 241. It is not possible to draw any firm conclusion from this, as the degree of distension of the intestine by the fixative was not standardized, and there may also have been different degrees of shrinkage of the tissue during fixation. The possibility that the injection medium had travelled less far toward the periphery in the hypertensive cases was considered, and an attempt was made to check this by counting the uninjected arterioles; but this had to be abandoned as it proved impossible to differentiate with certainty very small uninjected arterioles from venules. 
No important intimal thickening was seen in any of the arterioles in the intestinal wall, but the superior mesenteric artery in one of the hypertensive cases (E.C.) was greatly narrowed near its origin from the aorta by organized thrombus. The lumen at this point was reduced to $7 \mathrm{sq}$. mm. or approximately 25 per cent of the normal undistended lumen.

\section{RESULTS}

A. Wall/lumen Ratio. The 204 arterioles from the 6 hypertensive cases were ranged in order of size and divided into 10 equal subgroups. The mean wall/lumen ratio was then calculated for each of these 10 subgroups. The 241 arterioles from the 6 control cases were treated similarly. The mean value for the 10 per cent largest arterioles in the hypertensive series was then compared with the mean value for the 10 per cent largest arterioles in the control series, and so on for the remaining subgroups (Table II and Fig. 3). When this was done, it was found that the wall/lumen ratio of the arterioles in the hypertensive series was greater than that of the corresponding arterioles in the control series in the case of every subgroup except for the 20 per cent smallest arterioles.

If instead of subdividing the arterioles into 10 subgroups, each containing 10 per cent of the arterioles, the 200 largest arterioles in each series were subdivided into 10 subgroups, each containing 20 arterioles, the wall/lumen ratio was found to be greater in the hypertensive series than in the control series for all subgroups.

When the mean wall/lumen ratio of the 10 largest arterioles from each individual case was calculated it was found (Table III) that 5 of the 6 hypertensive cases had values of over 9 per cent, while only one (J.N.) of the control cases had a value of this order.

B. Cross-sectional Area of Wall. The arterioles were similarly subdivided and compared in respect of cross-sectional area of wall (Table IV and Fig. 4). When this was done, it was found that the cross-

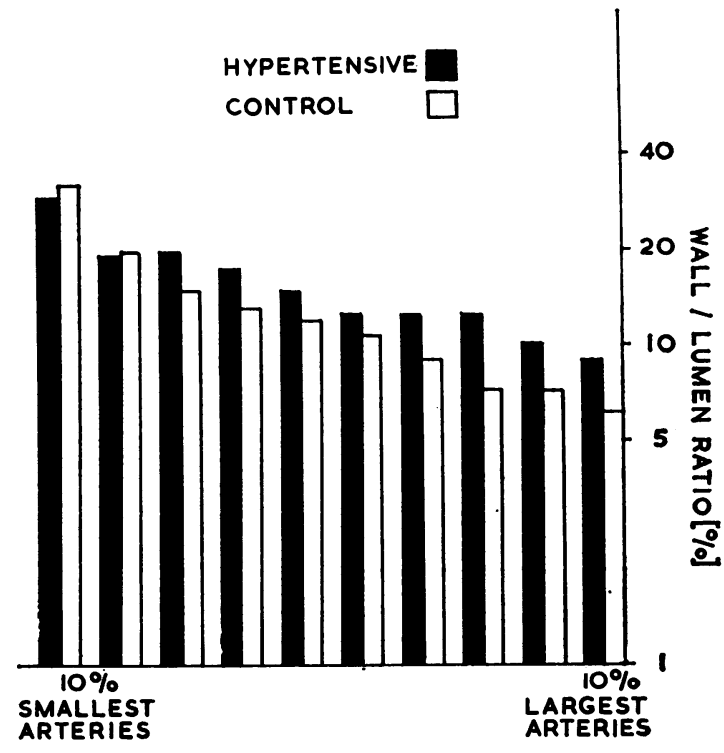

FIG. 3.-Wall/lumen ratios in the hypertensive and control series. In the hypertensive series, the wall/lumen ratio is greater than in the control series in all except the 20 per cent smallest arteries.

sectional area of wall in the hypertensive series did not exceed that in the control series except marginnally in the 10 per cent largest arterioles.

If instead of subdividing the arterioles into 10 subgroups, each containing 10 per cent of the arteries, the 200 largest arteries in each series were subdivided into 10 subgroups, each containing 20 arterioles, the cross-sectional area of wall is found to be less in the hypertensive series than in the control series for all sizes of arteriole.

When the mean cross-sectional area of wall of the 10 largest arterioles in each individual case was calculated, it was found (Table III) that all the cases in the control series had values within the range $800-2500$ sq. $\mu$. Three of the cases in the

TABLE II

WALL/LUMEN RATIOS IN HYPERTENSIVE AND CONTROL SERIES

\begin{tabular}{|c|c|c|c|c|c|c|c|c|c|c|c|}
\hline \multicolumn{6}{|c|}{ A. All arteries subdivided into 10 subgroups } & \multicolumn{6}{|c|}{$\begin{array}{c}\text { B. The } 200 \text { largest arteries in each series subdivided into } 10 \\
\text { subgroups }\end{array}$} \\
\hline & & & Hypertensive & Control & & & \multirow[b]{2}{*}{$\begin{array}{l}\cdots \\
\cdots \\
\cdots \\
\cdots \\
\cdots \\
\cdots \\
\cdots\end{array}$} & \multirow[b]{2}{*}{$\begin{array}{c}\text { Hypertensive } \\
9 \cdot 0 \% \\
10 \cdot 2 \\
12 \cdot 2 \\
12 \cdot 2 \\
13 \cdot 0 \\
14.4 \\
16.5 \\
19 \cdot 5 \\
17 \cdot 2 \\
29.5\end{array}$} & \multirow[b]{2}{*}{$\begin{array}{c}\text { Control } \\
5 \cdot 8 \% \\
7 \cdot 6 \\
6 \cdot 7 \\
8 \cdot 5 \\
9 \cdot 3 \\
10 \cdot 9 \\
12 \cdot 6 \\
12 \cdot 6 \\
14 \cdot 7 \\
15 \cdot 3\end{array}$} \\
\hline $\begin{array}{l}10 \% \text { larges } \\
\text { 2nd } 10 \% \\
\text { 3rd } \\
\text { 4th.. } \\
\text { 5th.. } \\
\text { 6th... } \\
\text { 7th... } \\
\text { 8th.. } \\
9 \text { th . } \\
10 \% \text { small }\end{array}$ & 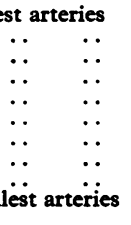 & $\begin{array}{l}\cdots \\
\cdots \\
\cdots \\
\cdots \\
\cdots \\
\cdots \\
\cdots\end{array}$ & $\begin{array}{l}\cdots \\
\cdots \\
\cdots \\
\cdots \\
\cdots \\
\cdots \\
\cdots\end{array}$ & $\begin{array}{l}9.0 \% \\
10.2 \\
12.3 \\
12.4 \\
12.4 \\
14.7 \\
17.2 \\
19.5 \\
19.1 \\
29.0\end{array}$ & $\begin{array}{l}6 \cdot 2 \% \\
7 \cdot 3 \\
7 \cdot 2 \\
9 \cdot 0 \\
10 \cdot 8 \\
12 \cdot 1 \\
13 \cdot 3 \\
14 \cdot 8 \\
19 \cdot 8 \\
32 \cdot 0\end{array}$ & $\begin{array}{l}\text { 20 larges } \\
\text { 2nd } 20 \\
\text { 3rd } \\
\text { 4th } \\
5 \text { th } \\
\text { 6th } \\
\text { 7th } \\
\text { 8th } \\
9 \text { th } \\
\text { 10th }\end{array}$ & $\begin{array}{ll}\text { st } & \text { arteries } \\
\cdots & \cdots \\
\cdots & \cdots \\
\cdots & \cdots \\
\cdots & \cdots \\
\cdots & \cdots \\
\cdots & \cdots \\
\cdots & \cdots\end{array}$ & $\begin{array}{l}\cdots \\
\cdots \\
\cdots \\
\cdots \\
\cdots \\
\cdots \\
\cdots\end{array}$ & & & \\
\hline
\end{tabular}


TABLE III

WALL/LUMEN RATIOS, CROSS-SECTIONAL AREAS OF WALL, AND INTERNAL DIAMETER AT 75TH PERCENTILE IN INDIVIDUAL CASES

\begin{tabular}{|c|c|c|c|c|c|}
\hline \multicolumn{3}{|c|}{$\begin{array}{l}\text { Case, age (yr.), } \\
\text { and sex }\end{array}$} & Wall/lumen ratio & Cross-sectional area of wall & $\begin{array}{l}\text { Internal diameter at } 75 \text { th per- } \\
\text { centile }\end{array}$ \\
\hline $\begin{array}{l}\text { Control } \\
\text { N.D. } \\
\text { G.H. } \\
\text { E.W. } \\
\text { J.N. } \\
\text { F.H. } \\
\text { H.S. }\end{array}$ & $\begin{array}{l}44 \\
47 \\
55 \\
61 \\
78 \\
78\end{array}$ & $\begin{array}{l}\mathbf{F} \\
\mathbf{M} \\
\mathbf{F} \\
\mathbf{M} \\
\mathbf{F} \\
\mathbf{M}\end{array}$ & $\begin{array}{l}\text { Mean of } 10 \text { la } \\
8 \cdot 2 \% \\
5 \cdot 3 \\
7 \cdot 0 \\
10 \cdot 6 \\
7 \cdot 9 \\
6 \cdot 7\end{array}$ & $\begin{array}{c}\text { ries in each case } \\
1760 \text { sq. } \mu \\
920 \\
2452 \\
1351 \\
1898 \\
1313\end{array}$ & $\begin{array}{r}72 \mu \\
111 \\
84 \\
62 \\
124 \\
119\end{array}$ \\
\hline $\begin{array}{c}\text { Hypertensive } \\
\text { W.M. } \\
\text { H.L. } \\
\text { J.S. } \\
\text { R.F. } \\
\text { E.C. } \\
\text { A.T. }\end{array}$ & $\begin{array}{l}42 \\
51 \\
68 \\
71 \\
72 \\
82\end{array}$ & $\begin{array}{l}\mathbf{M} \\
\mathbf{M} \\
\mathbf{M} \\
\mathbf{F} \\
\mathbf{M} \\
\mathbf{F}\end{array}$ & $\begin{array}{r}9 \cdot 9 \\
9 \cdot 9 \\
5 \cdot 0 \\
12 \cdot 3 \\
15 \cdot 4 \\
14 \cdot 6\end{array}$ & $\begin{array}{r}479 \\
2175 \\
313 \\
1058 \\
3435 \\
833\end{array}$ & $\begin{array}{r}59 \\
66 \\
60 \\
55 \\
111 \\
58\end{array}$ \\
\hline
\end{tabular}

hypertensive series fell within this range; two fell below it, and only one (Case E.C.) above it.

Comment. The finding of an increased wall/ lumen ratio in hypertension agrees with previously reported studies on uninjected material (Kernohan et al., 1929; Morlock, 1939), but the finding that there is no increase in cross-sectional area of wall is a surprise, and raises the question: Why is the wall/lumen ratio increased? Presumably, because the lumen is decreased. In order to check this, the

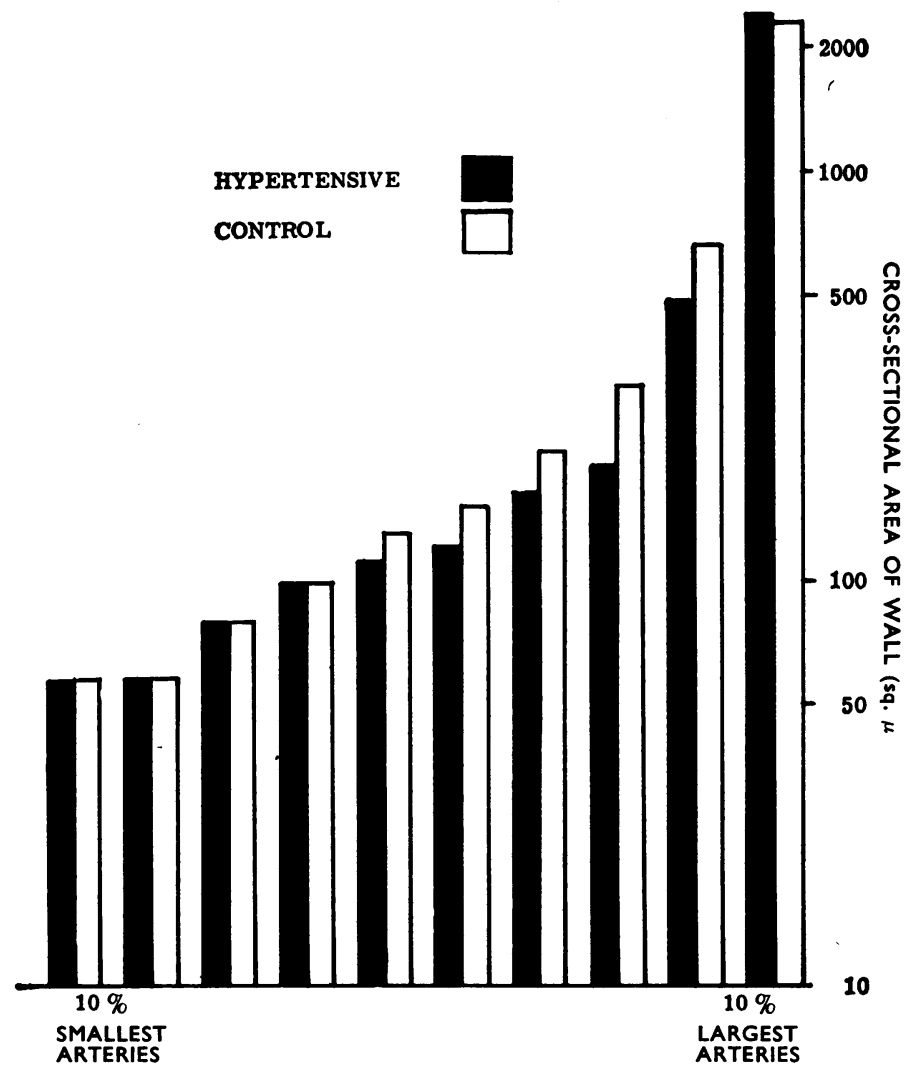

FIG. 4.-Cross-sectional area of wall in the hypertensive and control series. In the hypertensive series, the cross-sectional area of wall is either the same as, or less than, that in the control series, except marginally in the 10 per cent largest arteries. 
TABLE IV

CROSS-SECTIONAL AREA OF WALL IN HYPERTENSIVE AND CONTROL SERIES

\begin{tabular}{|c|c|c|c|c|c|c|c|c|c|}
\hline \multicolumn{5}{|c|}{ A. All arteries subdivided into 10 subgroups } & \multicolumn{5}{|c|}{$\begin{array}{c}\text { B. The } 200 \text { largest arteries in each series subdivided into } 10 \\
\text { subgroups }\end{array}$} \\
\hline & & Hypertensive & Control & \multicolumn{2}{|c|}{20 largest arteries } & \multirow[b]{2}{*}{$\begin{array}{l}\cdots \\
\cdots \\
\cdots \\
\cdots \\
\cdots \\
\cdots \\
\cdots\end{array}$} & Hypertensive & Control \\
\hline 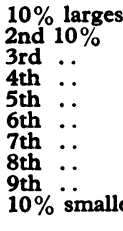 & $\begin{array}{cc}\text { st } & \text { arteries } \\
\ldots & \ldots \\
\cdots & \ldots \\
\ldots & \ldots \\
\ldots & \ldots \\
\ldots & \cdots \\
\ldots & \cdots \\
\cdots & \cdots \\
\text { est } & \text { arteries }\end{array}$ & $\begin{array}{l}\cdots \\
\cdots \\
\cdots \\
\cdots \\
\cdots \\
\cdots \\
\cdots\end{array}$ & $\begin{array}{c}3140 \text { sq. } \mu \\
616 \\
244 \\
212 \\
156 \\
146 \\
126 \\
103 \\
72 \\
71\end{array}$ & $\begin{array}{c}3020 \text { sq. } \mu \\
860 \\
388 \\
266 \\
201 \\
168 \\
127 \\
105 \\
72 \\
74\end{array}$ & $\begin{array}{ll}\text { 20 largest a } \\
\text { 2nd 20 } \\
\text { 3rd } & \ldots \\
\text { 4th } & \ldots \\
\text { 5th } & \ldots \\
\text { 6th } & \ldots \\
\text { 7th } & \ldots \\
\text { 8th } & \ldots \\
\text { 9th } & \ldots \\
\text { 10th } & \cdots\end{array}$ & $\begin{array}{l}\text { ies } \\
\ldots \\
\ldots \\
\ldots \\
\ldots \\
\ldots \\
\ldots\end{array}$ & & $\begin{array}{c}3229 \text { sq. } \mu \\
655 \\
312 \\
215 \\
176 \\
142 \\
126 \\
112 \\
67 \\
83\end{array}$ & $\begin{array}{c}3233 \text { sq. } \boldsymbol{\mu} \\
1192 \\
552 \\
336 \\
234 \\
193 \\
179 \\
117 \\
114 \\
88\end{array}$ \\
\hline
\end{tabular}

two series were compared with respect to the internal and external diameters of the arterioles.

C. Diameters. The arterioles were again ranged in order of size in regard to the internal diameter and convenient percentiles were calculated (i.e. the measurement below which a given percentage of the arterioles falls; e.g. the 90th percentile $=$ the measurement below which 90 per cent of the internal diameters fall). When the two series were compared (Table V and Fig. 5) it was evident that at every percentile between the 10th and the 90 th the internal diameter was considerably less in the hypertensive than in the control series. Thus 90 per cent of the arterioles in the control series were under $208 \mu$, whereas 90 per cent in the hypertensive series were under $146 \mu$. Similarly, 75 per cent in the control series were under $100 \mu$, whereas 75 per cent in the hypertensive series were under $70 \mu$. The trend was similar in the external diameters (Table V).

If, instead of comparing percentiles, the 200 largest arterioles in the hypertensive and control series were placed side by side, the differences were accentuated.

In the individual cases, there were insufficient arterioles to warrant calculation of the percentiles at 10 per cent intervals, so they were calculated at 25 per cent intervals. When the six control cases were compared with the six hypertensive cases (Fig. 6), it was found that the internal diameter at the 75th percentile was below $70 \mu$ in all but one (E.C.) of the hypertensive cases, and above $70 \mu$ in all but one (J.N.) of the control cases. The difference between the two groups is significant $(p=<0.05)$. There was no correlation between the

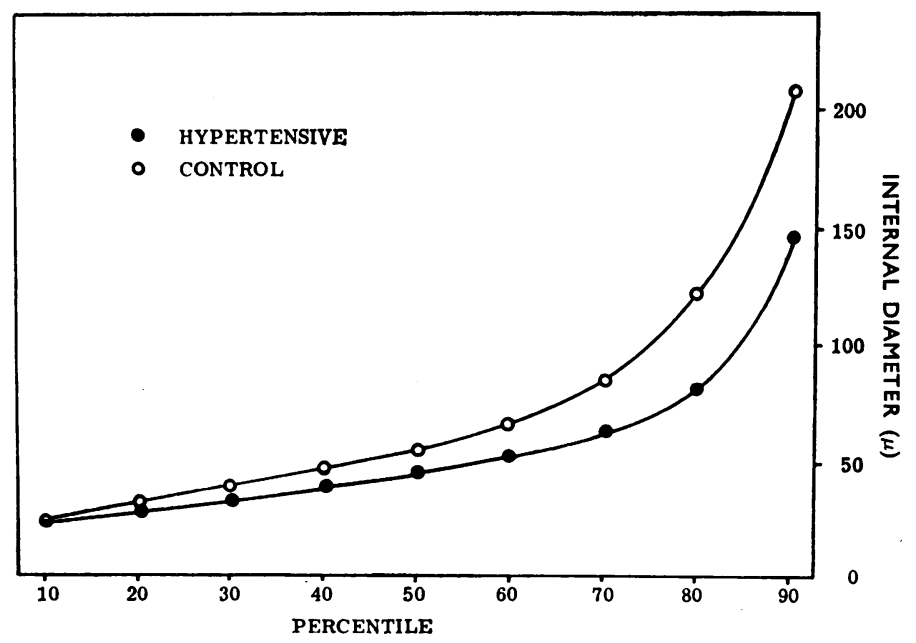

Fig. 5.-Internal diameters at various percentiles in the hypertensive and control series. At every percentile between 10 and 90 , the internal diameter of the arteries in the hypertensive series was less than that in the control series. For example, 90 per cent of the arteries in the hypertensive series had an internal diameter of less than $146 \mu$, whereas 90 per cent of the arteries in the control series had an internal diameter less than $208 \mu$. 
TABLE V ARTERIAL DIAMETERS IN HYPERTENSIVE AND CONTROL SERIES AT VARIOUS PERCENTILES

\begin{tabular}{|c|c|c|c|c|}
\hline \multirow{2}{*}{ Percentile } & \multicolumn{2}{|c|}{ External diameters $(\mu)$} & \multicolumn{2}{|c|}{ Internal diameters $(\mu)$} \\
\hline & Hypertensive & Control & Hypertensive & Control \\
\hline $\begin{array}{c}\text { Highest measurement } \\
90 \\
80 \\
70 \\
60 \\
50 \\
40 \\
30 \\
20 \\
10 \\
\text { Lowest measurement }\end{array}$ & $\begin{array}{r}450 \\
160 \\
88 \\
70 \\
60 \\
50 \\
45 \\
40 \\
34 \\
30 \\
20\end{array}$ & $\begin{array}{r}526 \\
224 \\
130 \\
90 \\
75 \\
59 \\
51 \\
45 \\
37 \\
30 \\
20\end{array}$ & $\begin{array}{l}428 \\
146 \\
80 \\
62 \\
52 \\
46 \\
39 \\
34 \\
28 \\
24 \\
16\end{array}$ & $\begin{array}{r}506 \\
208 \\
122 \\
84 \\
67 \\
54 \\
46 \\
39 \\
33 \\
24 \\
14\end{array}$ \\
\hline
\end{tabular}
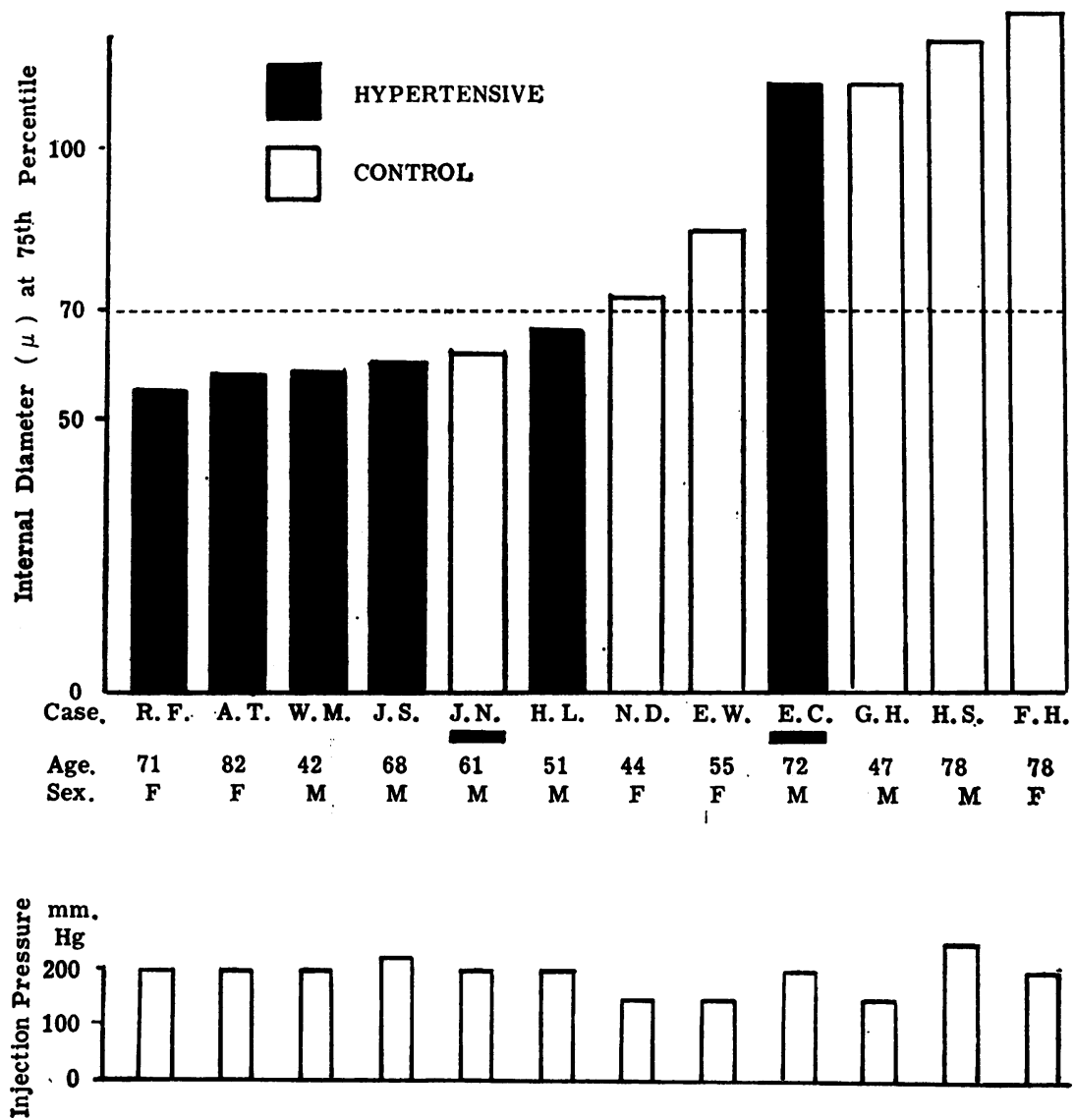

Fig. 6.-Internal diameter at the 75th percentile in the individual cases. This figure shows that in 5 of the 6 cases of hypertension the internal diameter at the 75th percentile was less than $70 \mu$, whereas in 5 of the 6 control cases, the internal diameter at the 75 th percentile was over $70 \mu$. The two exceptions are discussed in the text. There is no correlation between the internal diameter at the 75 th percentile, and age, sex, or injection pressure. 
75th percentile on the one hand, and age, sex, or injection pressure on the other.

The two exceptions call for a brief comment. Case E.C. undoubtedly had chronic hypertension but he also had severe stenosis of the superior mesenteric artery; and this may have protected the arteries beyond this point from the high blood pressure. Case J.N. had left ventricular hypertrophy and recurrent myocardial infarction. $\mathrm{He}$ was classified as a control case because there was no record of a blood pressure higher than $140 / 100 \mathrm{~mm}$. Hg. Nevertheless, the possibility of previous hypertension cannot be excluded.

\section{Discussion}

This study has shown that though the wall/lumen ratio of the intestinal arterioles is increased in hypertension, the cross-sectional area of the wall is not increased. There is, therefore, no hypertrophy or hyperplasia of these vessels. This is in contrast with the medium-sized mesenteric arteries (vasa recta), where slight hypertrophy has been demonstrated (Short and Thomson, 1959), and the larger branches of the superior mesenteric artery in which the hypertrophy is greater (Barrett, 1963).

If the increased wall/lumen ratio does not indicate hypertrophy or hyperplasia, what is its significance? On theoretical grounds, it can only mean a decreased diameter. That this is the explanation, was confirmed by comparing the diameters of the arterioles in the hypertensive and control groups, and finding that both the external and the internal diameters in the hypertensive group were less than those in the control group. To appreciate the full significance of this finding, it must be recalled that these measurements were made on arterioles which had been distended to such a degree that the internal elastic lamina had been rendered quite smooth. Furthermore, the hypertensive cases had been injected at a higher pressure than the controls in order to make sure of overcoming post-mortem contraction. Thus, intestinal arterioles in cases of chronic hypertension, distended to a point just short of rupture (in one or two cases the vessels had actually ruptured), have a smaller diameter than arterioles from control cases injected at a somewhat lower pressure. This finding fits in with the observations of Folkow, Grimby, and Thulesius (1958), Gaskell and Diosy (1959), Conway (1963), and others, who have demonstrated an abnormal resistance to blood flow through maximally dilated vascular beds in patients with chronic hypertension. In the present study, nervous and humoral mechanisms appear to be excluded, and the decreased diameter must be regarded as an intrinsic property of the vessels. These arterioles are obviously capable of

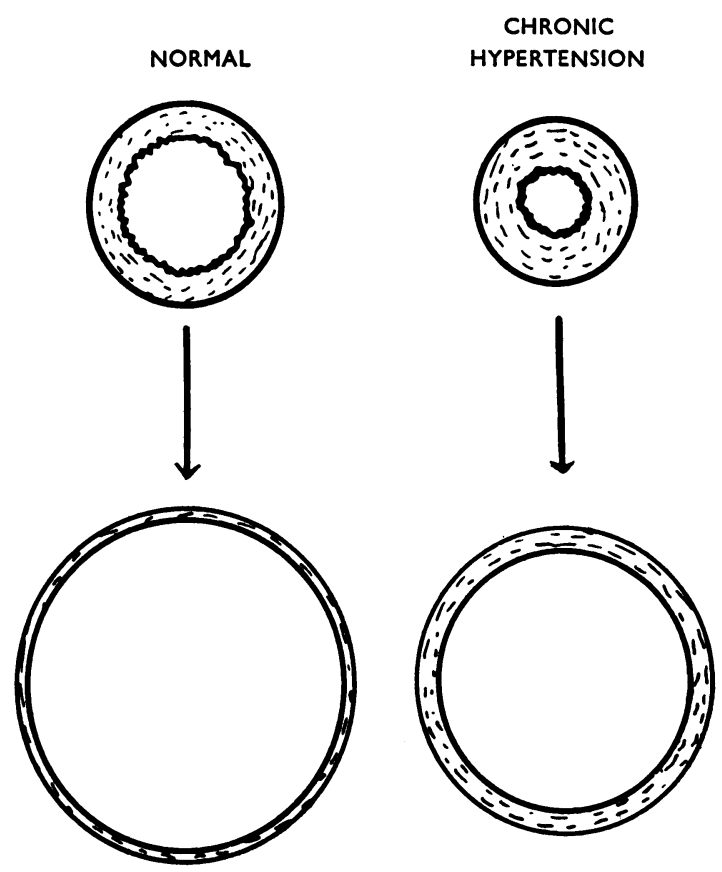

FIG. 7.-The state of the arterioles in chronic hypertension. Above, the arterioles are shown in a resting condition; below, in full distension. The arterioles in chronic hypertension are capable of wide variation in calibre, but cannot be distended as fully as normal. Both at rest and in full distension, the wall/lumen ratio is increased, but this is due to the decreased diameter and not to any increase in the cross-sectional area of the wall.

wide variation in calibre (see Fig. 1) but they cannot be distended as completely as normal arterioles. Their state is shown diagrammatically in Fig. 7. A similar condition has been demonstrated in the peripheral arteries of the lung in pulmonary hypertension (Short, 1957, 1959).

The nature of this arteriolar abnormality can only be conjectured at the present time. It could conceivably be either congenital or acquired. The fact that it was not demonstrable in Case E.C., with stenosis of the superior mesenteric artery, seems to fit better with an acquired ætiology. It is therefore postulated that prolonged arteriolar constriction from any cause leads to a persistent shortening of the circular muscle, perhaps involving some sort of "catch" mechanism (Johnson, 1962). The end result would then be analogous to the contracture that develops in skeletal muscle after division of its tendon (Ranson and Sams, 1928). Such muscle is capable of contraction and relaxation, but cannot relax to its normal length. Such a concept of arteriolar contracture would fit in with the current idea of hypertension as a state initiated by a variety 
of factors which later recede into the background as secondary vascular disease takes over as the major factor in maintaining the raised pressure. It is suggested that arteriolar contracture as here described is one of the forms of secondary vascular disease responsible for the maintenance of a high blood pressure.

\section{SUMMARY}

The wall/lumen ratio, cross-sectional area of wall, and calibre of the arterioles in the wall of the small intestine have been studied in 6 cases of chronic hypertension and 6 normotensive cases, following injection of the superior mesenteric artery with a suspension of bismuth oxychloride in gelatin at a pressure of $150-250 \mathrm{~mm}$. Hg. The hypertensive cases were generally injected at a somewhat higher pressure than the controls. The aim of the injection was to distend all arterioles down to a diameter of $20 \mu$ and so abolish the variable degree of postmortem contraction that is present in uninjected specimens. In all the cases studied, the undulation of the internal elastic lamina was completely abolished. Under these conditions, it was possible to obtain a valid measurement of diameter and wall thickness on every arteriole with a diameter of $20 \mu$ or over seen in any section.

The wall/lumen ratio of the arterioles was found to be increased in cases of hypertension, as previously reported in studies on uninjected tissues, but there was no increase in the cross-sectional area of the arteriolar wall; in other words, there was no hypertrophy or hyperplasia. Measurements of arteriolar calibre confirmed that the increase in wall/ lumen ratio was due to a decreased arteriolar diameter. The significance of this finding is enhanced when it is recalled that the arterioles were distended, and that the hypertensive cases were in general injected at a higher pressure than the controls. The evidence suggests that in chronic hypertension there is a persistent shortening of the circular elements in the arteriolar wall. This abnormality could conceivably be congenital, but it is considered more likely to be a result of prolonged arteriolar constriction in the early stages of hypertension. Once developed, it would probably become an important factor in maintaining the raised blood pressure. Because of the analogy with the myostatic contracture of skeletal muscle, this condition may provisionally be termed arteriolar contracture.

The author is glad to acknowledge the helpful criticisms of several colleagues at various stages in this work, though he cannot blame them for its residual defects. Special thanks are due to Dr. A. D. Thomson, Professor J. M. Ledingham, Professor A. R. Currie, and Sir George Pickering; as well as to Mr. W. Brass for advice regarding the statistical aspects.

\section{REFERENCES}

Barrett, A. M. (1963). Arterial measurements in the interpretation of cardiomegaly at necropsy: cardiac hypertrophy and myocardial infarction. $\mathcal{f}$. Path. Bact., 86, 9.

Conway, J. (1963). A vascular abnormality in hypertension. A study of blood flow in the forearm. Circulation, 27, 520.

Folkow, B. (1956). Structural, myogenic, humoral and nervous factors controlling peripheral resistance. In Hypotensive Drugs, ed. M. Harington, pp. 163-174. Pergamon Press, London.

-, Grimby, G., and Thulesius, O. (1958). Adaptive structural changes of the vascular walls in hypertension, and their relation to the control of the peripheral resistance. Acta physiol. scand., 44, 255.

Gaskell, P., and Diosy, A. (1959). Persistance of abnormally high vascular tone in vessels of the finger after digital nerve block in patients with chronic high blood pressure. Circulat. Res., 7, 1006.

Gull, W. W., and Sutton, H. G. (1872). On the pathology of the morbid state commonly called chronic Bright's disease with contracted kidney ("arterio-capillary fibrosis"). Med.-chir. Trans., 55, 273.

Johnson, W. H. (1962). Tonic mechanisms in smooth muscles. In Proc. Symposium on Vascular Smooth Muscle, 1961. Physiol. Rev., 42, Suppl. 5, p. 113.

Kernohan, J. W., Anderson, E. W., and Keith, N. M. (1929). The arterioles in cases of hypertension. Arch. intern. Med., 44, 395.

MacWilliam, J. A., and Mackie, A. H. (1908). Arteries, normal and pathological. Brit. med. $\mathcal{F}$., 2, 1477.

Morlock, C. G. (1939). Arterioles of the pancreas, liver, gastro-intestinal tract and spleen in hypertension. Arch. intern. Med., 63, 100.

Ranson, S. W., and Sams, C. F. (1928). A study of muscle in contracture: the permanent shortening of muscles caused by tenotomy and tetanus toxin. $\mathcal{F}$. Neurol. Psychopath., 8, 304.

Short, D. S. (1957). The arterial bed of the lung in pulmonary hypertension. Lancet, $2,12$.

- (1959). The application of arteriography to the pathological study of pulmonary hypertension. In Pulmonary Circulation, ed. W. R. Adams and I. Veith, pp. 233-241. Grune and Stratton, New York.

- and Thomson, A. D. (1959). The arteries of the small intestine in systemic hypertension. F. Path. Bact., 78, 321.

Van Citters, R., Wagner, B. M., and Rushmer, R. F. (1962). Architecture of small arteries during vasoconstriction. Circulat. Res., 10, 668. 